\title{
Review Article \\ Growth Hormone-Releasing Hormone and Its Analogues: Significance for MSCs-Mediated Angiogenesis
}

\author{
Xiangyang Xia, 1 Quanwei Tao, ${ }^{2}$ Qunchao Ma, ${ }^{3,4}$ Huiqiang Chen, \\ Jian'an Wang, ${ }^{3,4}$ and Hong $\mathrm{Yu}^{3,4}$ \\ ${ }^{1}$ Department of Ultrasound, The Second Affiliated Hospital of Zhejiang University School of Medicine, Hangzhou 310009, China \\ ${ }^{2}$ Hangzhou Leading Pharmatech Co., Ltd., Hangzhou 311100, China \\ ${ }^{3}$ Department of Cardiology, The Second Affiliated Hospital of Zhejiang University School of Medicine, Hangzhou 310009, China \\ ${ }^{4}$ Cardiovascular Key Laboratory of Zhejiang Province, Hangzhou 310009, China \\ ${ }^{5}$ Department of Cardiology, The Second Hospital of Shandong University, Jinan, Shandong 250033, China
}

Correspondence should be addressed to Hong Yu; yuvascular@zju.edu.cn

Received 9 November 2015; Revised 19 June 2016; Accepted 3 July 2016

Academic Editor: Qingzhong Xiao

Copyright (C) 2016 Xiangyang Xia et al. This is an open access article distributed under the Creative Commons Attribution License, which permits unrestricted use, distribution, and reproduction in any medium, provided the original work is properly cited.

\begin{abstract}
Mesenchymal stromal cells (MSCs) are promising candidates for regenerative medicine because of their multipotency, immuneprivilege, and paracrine properties including the potential to promote angiogenesis. Accumulating evidence suggests that the inherent properties of cytoprotection and tissue repair by native MSCs can be enhanced by various preconditioning stimuli implemented prior to cell transplantation. Growth hormone-releasing hormone (GHRH), a stimulator in extrahypothalamus systems including tumors, has attracted great attentions in recent years because GHRH and its agonists could promote angiogenesis in various tissues. GHRH and its agonists are proangiogenic in responsive tissues including tumors, and GHRH antagonists have been tested as antitumor agents through their ability to suppress angiogenesis and cell growth. GHRH-R is expressed by MSCs and evolving work from our laboratory indicates that treatment of MSCs with GHRH agonists prior to cell transplantation markedly enhanced the angiogenic potential and tissue reparative properties of MSCs through a STAT3 signaling pathway. In this review we summarized the possible effects of GHRH analogues on cell growth and development, as well as on the proangiogenic properties of MSCs. We also discussed the relationship between GHRH analogues and MSC-mediated angiogenesis. The analyses provide new insights into molecular pathways of MSCs-based therapies and their augmentation by GHRH analogues.
\end{abstract}

\section{Introduction}

Growth hormone $(\mathrm{GH})$, secreted by the somatotropes in the anterior part of pituitary gland, is the predominant hormone that regulates linear growth. Its production and secretion are controlled by growth hormone-releasing hormone (GHRH), along with the somatostatin, GH itself, and downstream factors such as insulin growth factor 1 (IGF-1). GHRH and its receptors are expressed not only in the hypothalamus and pituitary but also in peripheral tissues. Thus, in addition to modulating GH release, GHRH indirectly regulates the proliferation of cells in multiple other tissues including tumor cells through a GHRH/GH/IGF-1 axis. GHRH can also directly regulate cell growth through paracrine/endocrine mechanisms by binding to the GHRH receptor on target cells.
Because of this, synthetic agonists and antagonists of GHRH have attracted wide attention in recent years as global regulators of cell growth with therapeutic potential including tissue regeneration and tumor suppression, respectively. GHRH has been shown to stimulate angiogenesis in human neuroendocrine tumors by promoting VEGF secretion [1]. Agonists of GHRH applied to the post infarct myocardium improved cardiac remodeling and helped resolve ischemia [2]. GHRH antagonists have been widely used to inhibit angiogenesis and proliferation of tumor cells in prostate cancer [3], endometrial cancer [4], non-small cell lung cancer [5], and ovarian cancer [6].

Mesenchymal stromal cells (MSCs), produced in the bone marrow as well as peripheral tissues, are recognized by their plastic adherence, expression of a panel of specific cell 
surface markers, and multipotent differentiation potential. In part because of their multipotency and immune-privilege properties, MSCs have been widely used to promote tissue regeneration including reconstruction of blood vessels $[7,8]$, cardiac repair [9], and angiogenesis [10-12]. However, the full regenerative potential of MSCs for clinical application is limited by poor posttransplantation engraftment and survival of native MSCs in the adverse microenvironment of a myocardial infarct of other ischemic circumstance [13]. Various interventions have been used with some success to enhance MSC survival including genetic modification [14], hypoxia preconditioning $[15,16]$, and pretreatment with chemical agents such as erythropoietin and unsaturated fatty acids $[17,18]$. Work from our laboratory and others confirms that GHRH and its analogues can enhance angiogenesis in the infarcted heart and markedly enhance the regenerative properties of MSCs [19, 20]. Other laboratories have also clearly shown the converse that GHRH antagonists powerfully inhibit angiogenesis and growth of lung cancer cells [21], prostate cancer cells [22], glioblastomas cells [23], and breast cancer cells [24]. Therefore, we speculate that GHRH is a natural modulator of MSC activity, and agonists or analogues of GHRH may be the key to optimizing the regenerative properties of these cells for cardiovascular indications.

Here, we summarize current knowledge on the effects of GHRH analogues on normal and malignant cells and the potential application of GHRH analogues to optimize the proangiogenic and reparative properties of MSCs.

\section{GHRH and Its Analogues}

2.1. The GHRH/GH/IGF-1 Axis. The GHRH/GH/IGF-1 axis is a fundamental endocrine regulatory pathway that contributes to physical and metabolic homeostasis [26]. GHRH is synthesized and stored in the hypothalamus and transported to the pituitary gland where it activates signaling by binding to a specific receptor (GHRH-R) on the pituitary. $\mathrm{GH}$ is stimulated by GHRH and secreted by somatotropes in the anterior part of pituitary. Circulating GH exerts its influence by directly binding to a range of cell types with $\mathrm{GH}$ receptors or by indirect interaction with IGF-1 [25]. IGF-1 is produced mostly by liver and muscle and regulates cell proliferation, differentiation, and maturation in multiple tissues such as bone, cartilage, skeletal muscle, adipocyte, and cardiomyocyte. By crosstalk with the IGF-1 signaling pathway, GHRH$\mathrm{GH}$ contributes to fundamental physiology, metabolism, and organismal growth including epidermis, connective tissue and bone, wound healing, and blood homeostasis including glucose and lipid control [27]. Circulating GH levels are regulated through long-loop feedback and short-loop feedback mechanisms of GHRH/GH/IGF-1 axis. Because GHRH communicates both through the GHRH/GH/IGF-1 axis and by direct binding to GHRH-R on periphery cells, there is a huge therapeutic potential for its analogues both agonist and antagonist to treat disease that may be associated with any imbalance of GHRH/GH secretion [28].

2.2. GHRH Agonists. GHRH agonists are analogues of native human GHRH that have chemically modified amino acid sequences. They were initially synthesized as substitutes to treat growth hormone deficiency (GHD) [29, 30]. Since the agonists exhibit higher activity and better stability compared with the natural GHRH, they are even more suitable for clinical application [43].

In addition to their well-documented ability to stimulate the GH secretion, GHRH agonists affect peripheral tissues by direct receptor binding and stimulating cell proliferation. Multiple cell types may be affected; for example, Dioufa et al. reported that the GHRH agonist JI-38 enhanced wound healing by activating fibroblasts via a fibroblast splice variant of the native GHRH receptor [31,32]. The GHRH agonist MR-403 was shown to have a cytoprotective effect on rat islet cocultured with adrenal cells [44]. Recently a series of new selective and more potent GHRH agonistic analogues have been produced and are being developed for clinical application. These include MR-356, MR-361, and MR-367 [45].

For cardiovascular indications, GHRH-R was recently found to be expressed by rat cardiomyocytes and administration of exogenous GHRH blocked apoptosis and reduced the cardiac scar size after myocardial infarction. The effects correlated with GHRH-R-mediated activation of reperfusion injury salvage kinase (RISK) and other survival kinase pathways including extracellular regulated protein kinases (ERK) 1/2, phosphatidylinositol 3-kinase (PI3K)/Akt and adenylate cyclase (AC)/cyclic adenosine monophosphate (cAMP)/protein kinase A (PKA), glycogen synthase kinase$3 \beta$, and the signal transducer and activator of transcription- 3 (STAT3) signaling pathways $[33,34]$. In an extension of this, subcutaneous administration of the potent GHRH agonist MR-409 was recently shown to exert powerful cardioprotection in a swine AMI model [35]. Application of MR-409 did not affect the heart weight/body weight index and was without any detectable adverse effects supporting safety in a large animal model. The authors concluded that systemic GHRH agonists protect the heart and preserve cardiac function during and after infarction by activating GHRH receptors on cardiomyocytes. Other studies confirm the cardioprotective, reparative functions of GHRH agonist administration and have demonstrated significant downregulation of inflammatory cytokines including IL-2, IL-6, and IL-10 in response to such agonists in vivo [36]. GHRH agonist JI-38 was shown to increase SDF-1 expression and stem cells homing in a rat model of AMI, thereby promoting cardiac repair and angiogenesis [2]. Therefore, GHRH and its agonists may play important roles in the integrity and resilience of peripheral tissues, including the heart and coronary vasculature.

2.3. Antitumor Effects of GHRH Antagonists. GHRH and GHRH-R are expressed in diverse tumor cells including human breast, endometrial, and ovarian cancers. Such locally generated GHRH circuits in tumor cells trigger bioactive and immune responses that directly impact tumor cell proliferation and expansion. Plasma GHRH levels under normal (nontumorigenic) conditions are low to undetectable because of rapid clearance and there is sparse evidence that naturally circulating GHRH contributes to tumorigenesis [46]. However, GHRH antagonists may be able to suppress the 


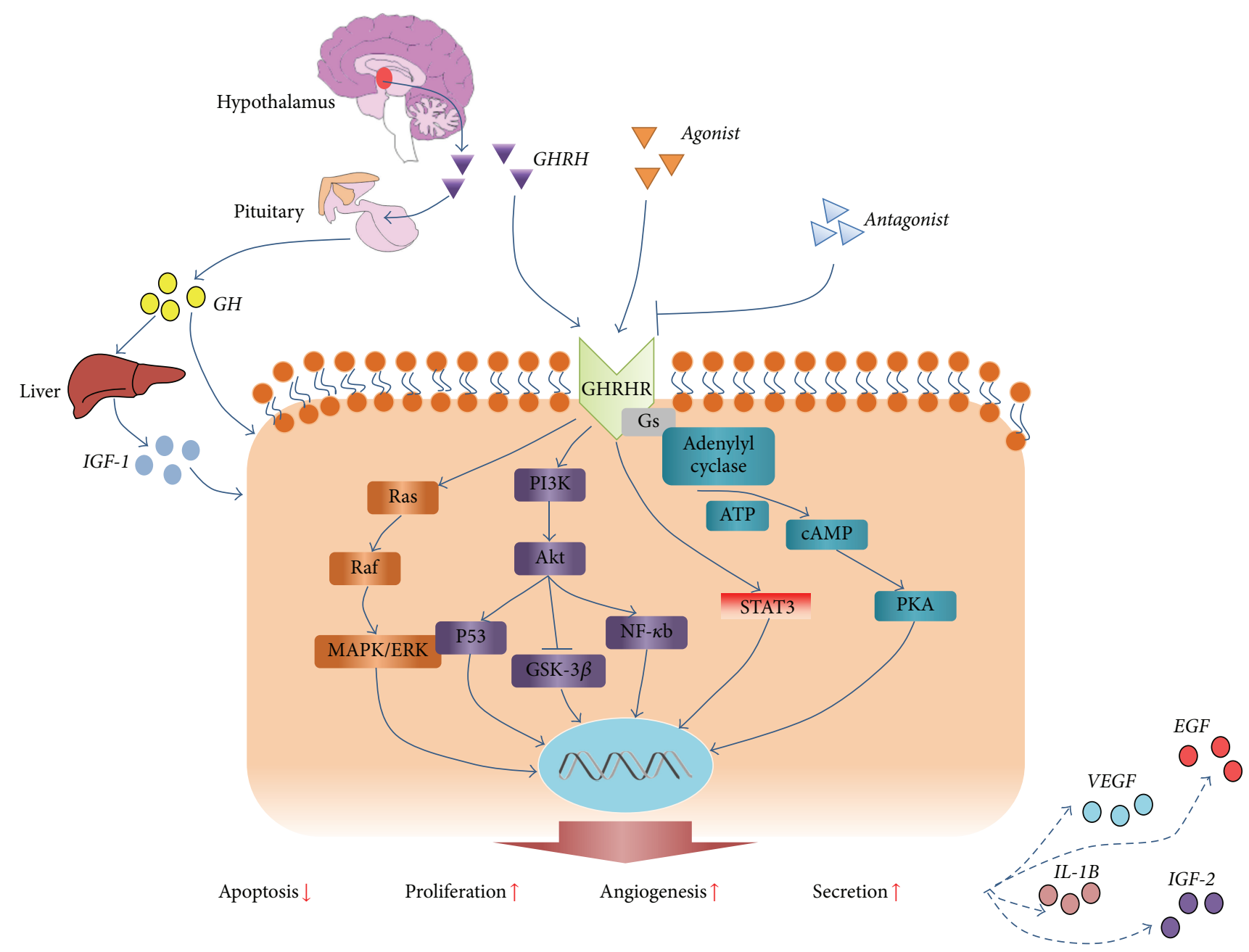

FIGURE 1: Cellular effects of GHRH analogues. GHRH is secreted by the hypothalamus and binds to GHRH-Rs on the pituitary to stimulate secretion of GH and downstream activity of IGF-1. GHRH and its agonists can bind directly to GHRH-Rs on multiple cell types of endocrine and nonendocrine origin. Signaling pathways that are activated by GHRH and its agonists include AC/cAMP/PKA, Ras/Raf/ERK, PI3K/Akt, and STAT3. Mediation through these signaling pathways leads to enhanced cell survival, proliferation, and secretion of cytokines. GHRH antagonists inhibit these pathways by competitively binding to the GHRH-R.

tumor progression by counteracting the localized circuits of GHRH/GHRH-R that are active in the tumor microenvironment. GHRH antagonists act as competitors of GHRH for binding to GHRH-R thereby blocking GHRH-R activation [47]. This provides us a novel approach to treat cancer with GHRH antagonists. For the past 25 years the antitumor properties of GHRH antagonists have been studied on cancer cell lines from breast, prostate, pancreas, colon, lung, ovarian, brain, and lymphocyte [23, 24, 37-42]. GHRH was shown to cause MAPK activation in MDA-MB-231 breast cancer cells via phosphorylation of Ras and Raf, and the GHRH antagonists MZ-J-7-138 and JV-1-92 were shown to block this pathway and suppress lung carcinoma growth in a manner that correlated with Ras inhibition [40,48]. It was further demonstrated that the GHRH antagonist JMR-132 inhibited prostate cancer cell growth by suppressing Akt and ERK pathways [49]. All these studies confirm the complexity of growth regulation and signaling pathways in tumor cells that expose multiple potential targets for GHRH and its antagonists.

Angiogenesis is a central activity that controls the growth, expansion, and metastasis of tumors [50], which has been used as a primary target for the antitumor actions of GHRH antagonists. The GHRH antagonist MZ-J-7-114 was shown to block the activities of VEGF and downregulate the expression of epidermal growth factor (EGF) and VEGF receptors, thereby effectively abolishing angiogenesis and tumor growth [5]. The effects of GHRH analogues and their discriminative roles on normal versus tumor cells are summarized in Figure 1 and Table 1.

2.4. Interaction between GHRH and Other Hormones. GHRH regulation of GH secretion through GHRH/GH/IGF-1 is well established. GH secretion is also regulated indirectly by GHRH interactions with other hormones. Ghrelin is a 28amino acid peptide produced by cells in the gastrointestinal tract that regulates $\mathrm{GH}$ release in a dose dependent manner 
TABLE 1: Effects of GHRH and its analogues.

\begin{tabular}{|c|c|c|c|c|}
\hline & GHRH & GHRH agonists & $\begin{array}{c}\text { GHRH } \\
\text { antagonists }\end{array}$ & $\begin{array}{l}\text { Differences between GHRH } \\
\text { and analogues }\end{array}$ \\
\hline Promote GH secretion & $\begin{array}{c}++ \\
{[25-28]}\end{array}$ & $\begin{array}{c}++ \\
{[29,30]}\end{array}$ & - & Quantitative \\
\hline Cell proliferation & I & $\stackrel{+}{+}[31,32]$ & - & Qualitative and quantitative \\
\hline $\begin{array}{l}\text { Cardiac protection (reduce infarct size, ameliorate } \\
\text { cell apoptosis, and restore heart function) }\end{array}$ & l & $\stackrel{+}{+}$ & - & Qualitative and quantitative \\
\hline $\begin{array}{l}\text { Antitumor effect (suppress tumor cell } \\
\text { proliferation and angiogenesis) }\end{array}$ & - & - & $\begin{array}{c}+++ \\
{[23,24,37-42]}\end{array}$ & Qualitative and quantitative \\
\hline
\end{tabular}

Note:,+++ , and +++ represent positive effect: + for mild effect, ++ for moderate, and +++ for significant and strong effect; - represents suppressive effect; / represents no effect.

[51]. Ghrelin is a more potent stimulator of $\mathrm{GH}$ release than GHRH and the combined effect of ghrelin and GHRH on GH release is additive. GHRH and ghrelin bind independently to GHS and GHRH receptors with corresponding effects downstream [52]. Ghrelin activates the hypothalamic-pituitaryadrenal axes to regulate sleep. GHRH stimulates slow-wave sleep while corticotrophin-releasing hormone $(\mathrm{CRH})$ antagonizes these pathways and stimulates wakefulness. CRH can strengthen the ghrelin-induced cortisol secretion but has no direct effect on $\mathrm{GH}$ release, while $\mathrm{GHRH}$ opposes $\mathrm{CRH}$ [53]. Interactions between GHRH, ghrelin, and sex steroids are synergistic and short-term beta estradiol application in postmenopausal women enhances ghrelin efficiency in the presence of GHRH [54].

\section{MSCs Promote Angiogenesis}

MSCs are multipotent stem cells that can differentiate into multiple cell lineages including osteoblasts, chondrocytes, adipocytes, myoblasts, fibroblasts, and stromal cells. MSCs can also be stimulated to express markers of cardiomyocytes, hepatocytes, and endothelial cells [55]. Based on their broad regenerative and immune-privileged properties, MSCs have been widely tested for use in regenerative medicine, in particular myocardial infarction and the related promotion of angiogenesis and vasculogenesis [56-64]. MSCs promote angiogenesis by the following actions: (1) secretion of trophic factors such as VEGF-A and chemoattractive cytokines [65]; (2) organization of pericytes and endothelial support cells during neovascularization [66, 67]; (3) stimulation of endogenous endothelial regenerative progenitor cells (EPCs) during ischemic injury [68]; (4) immune regulation of the microenvironment to enhance cell survival and angiogenesis $[69,70]$.

3.1. Paracrine Effects of MSCs. The proangiogenic stimuli of MSCs are widely believed to be mediated by paracrine pathways particularly through the actions of VEGF-A, $\beta$ FGF, and SDF- $\alpha[65,71,72]$. Cysteine-rich protein 61 (Cyr61 or aka CCN1) is a novel proangiogenic factor that belongs to the CCN family. Cyr61 is secreted by MSCs and contributes importantly to the paracrine proangiogenic effect especially in damaged tissues [10]. Capillary growth requires degradation of the surrounding extracellular matrix (ECM) to allow endothelial cell sprouting [66]. Matrix metalloproteinases including MMP2, MMP9, and MMP14 are secreted by MSCs and target the ECM through distinct proteolytic actions thereby modulating the microenvironment and promoting appropriate interactions between MSCs and endothelial cells [66]. GATA-4 is a zinc finger transcription family that plays a key role in regulating the proangiogenic paracrine actions of MSCs. Overexpression of GATA-4 in MSCs enhances the angiogenic actions of MSCs by augmenting the secretion of multiple proangiogenic factors including VEGFA, IGF-1, and vWF [73]. MSCs stimulate upregulation of VEcadherin and recruitment of $\beta$-catenin to endothelial cells, which are vital for the integrity of endothelial barriers and junctions [74]. MSCs also secrete a rich mixture of cytokines and immune-modulating factors that enhance angiogenesis directly and indirectly.

3.2. MSC Function as Pericytes and Vascular Cells. MSCs can function as perivascular cells or pericytes that accumulate around the vessels in the MSC niche [8]. These cells provide structural support and may constitute a reservoir of undifferentiated precursor cells for tissue regeneration [75]. Pericytes and MSCs share common cell surface markers and are both multipotent [76]. Pericytes may be viewed as vascular MSCs that can migrate under appropriate stimulation from the MSC vascular niche to the vascular tube where they regulate the neovascularization by secreting bioactive cytokines such as VEGF-A [77]. The high migratory capability of MSCs allows them to be recruited to multiple targets in vivo, including damaged tissues and tumors such as glioma where they can integrate as pericytes. As such MSCs may be used as selective antitumor drug transfer vehicles [78].

It has also been shown that the pericytes or vascular MSCs present in the aortic artery may modulate restenosis after arterial injury. Engrafted MSCs with endothelial-like phenotypes were shown to express endothelial nitric oxide synthase (eNOS) and may retard the processes of restenosis [79]. In contrast to this, other research suggests that MSCs preferentially migrate to the medial zone of blood vessels and differentiate into vascular smooth muscle cells [80]. Therefore, the direction of MSC differentiation may be related to the tissue specific microenvironment. When cultured 
under endothelial differentiation conditions, MSCs express endothelial traits and markers possibly through the upregulation of forkhead box protein C2 (FOXC2) and its downstream target alpha v beta 3 integrin/CD6 [81]. VEGF-A stimulation of cultured MSCs also promotes endothelial-like differentiation by activating the Rho/Rho-associated coiled-coil containing protein kinase (ROCK) signaling pathway and myocardin-related transcription factor-A (MRTF-A) [82]. Physical stimuli such as modeled microgravity with or without VEGF can direct MSCs to express endothelial markers including Flk-1 and vWF $[83,84]$. Taken together these results confirm the multipotency of MSCs and support major roles in vascular regeneration including possible direct contributions to endothelial cell recruitment and sprout formation.

3.3. Stimulation of Endogenous Regenerative Programs. EPCs may contribute to the structure, organization, and architecture of regenerating blood vessels. In addition to their potential to generate mature endothelial cells, EPCs also mediate paracrine actions by secreting angiogenic cytokines especially at the early stages of vessel formation [85]. EPCs and MSCs cross-communicate at multiple levels and when cocultured both types of cells demonstrated enhanced proliferation and proangiogenic properties [86]. MSC-EPC intercellular signaling involves both paracrine effects and direct cell-to-cell communication [87, 88]. Simultaneous tissue transplantation of MSCs with EPCs promotes angiogenesis in a synergistic manner and conditioned medium from cocultures of EPCs and MSCs generate complementary sets of angiogenic cytokines and more efficiently promote angiogenesis of cultured endothelial cells under both normoxic and hypoxic culture conditions [89]. The results support synergism between EPCs and MSCs at multiple levels in the developing, regenerating vasculature, particularly involving secreted cytokines that promote cell recruitment, proliferation, and differentiation [90].

3.4. Immune Regulation. MSCs modulate immunoreactions by interacting with immune cells. MSCs inhibit the proliferation and maturation of B-cells and NK-cells and suppress the proliferation of $\mathrm{CD}^{+}$and $\mathrm{CD}^{+}$T-cells while wielding protective effect on other cells such as neutrophils [91]. MSCs can also inhibit lymphocyte proliferation as well as B-cells differentiation [55]. However, the precise mechanisms of MSCs-related immune regulation properties are not fully understood. A number of distinct pathways have been described. Firstly, MSCs can modulate immune cells by secreting related chemokines and cytokines. Activation of Toll-like receptors 3 and 4 on MSCs increases the production of IL-6, IL-8, and chemokine (C-X-C motif) ligand 10 (CXCL10) to suppress the proliferation of T-cells through Notch signaling [92]. Secondly, MSCs attract proinflammatory M1 macrophages through secreted cytokines CXCL2, macrophage inflammatory protein- $1 \alpha$ (MIP- $1 \alpha$ ), MIP-1 $\beta$, and growth-regulated protein $\beta[69,93]$. Thirdly, MSCs can recruit anti-inflammatory M2 macrophage by accumulated production and secretion of PEG 2 under mediation by $\gamma$-IFN to balance the inflammatory responses [94]. Furthermore,
MSCs can directly contact to endothelial cells by the functional adherens junctions mediated by VE-cadherins and $\beta$ catenin to maintain intact endothelial barriers. Endothelial barriers can prevent uncontrolled inflammation that would be caused by increased vascular permeability [74]. Immune regulation by MSCs helps support an appropriate microenvironment that is conducive to angiogenesis and the maturation of new blood vessels.

3.5. Preconditioning to Enhance the Viability of MSCs. Despite their unique properties, clinical applications of MSCs for tissue protection and regeneration are limited by poor survival and limited engraftment. Multiple preconditioning stimuli have been tested to improve posttransplantation survival and function. These include gene modification, physical and chemical preconditioning, and the pretransplantation culture microenvironment.

Physical preconditioning includes hypoxia preconditioning $[95,96]$, which can attenuate apoptosis caused by hypoxia/reoxygenation. Our group has shown that the superior performance of MSCs conferred by hypoxia precondition is mediated at least in part through a leptin-mediated mechanism [15]. Hydrogen gas and oxidative stress pretreatments were also successful preconditioning stimuli that improved survival of pretransplantation of MSCs [97, 98].

Paracrine stimulation by multiple growth factors, cytokines, and chemicals can confer protection and increased survival. The repertoire includes growth factors such as TGF- $\beta$ [99], TGF- $\alpha$ [99], erythropoietin (EPO) [17], epidermal growth factor [100], parathyroid hormone [101], and K-channel activator diazoxide [102, 103]. Such preconditioning can be implemented by pretreatment with recombinant proteins or by gene modification. For example, MSCs that overexpress GSK- $3 \beta$ by gene transfection have significantly improved cardioprotective properties compared with MSCs alone [104]. Similarly, MSCs that overexpress the surviving gene conferred superior recovery in a rat myocardial infarction model [105]. In a rapidly advancing research field of biomaterial engineering, it has been shown that 3-dimensional support systems that mimic the microenvironment of the ECM support markedly improved cell survival after transplantation. Such engineered scaffolds are being tested to deliver sheets of supportive cells to the myocardium and islets for treating diabetes and bone reconstruction $[106,107]$.

In summary multiple pretreatment strategies have been developed to enhance the performance of MSCs as ex vivo reagents for angiogenesis and tissue repair. To our knowledge none have been tested clinically but preclinical results indicate efficacy and safety of most protocols and support clinical translation. The known roles of MSCs in promoting angiogenesis are summarized in Figure 2.

\section{Functional Enhancement of MSCs by GHRH Agonists}

4.1. Expression of GHRH Receptor on MSCs. In addition to the hypothalamus and pituitary, GHRH receptors are expressed in multiple extrahypothalamic tissues including 

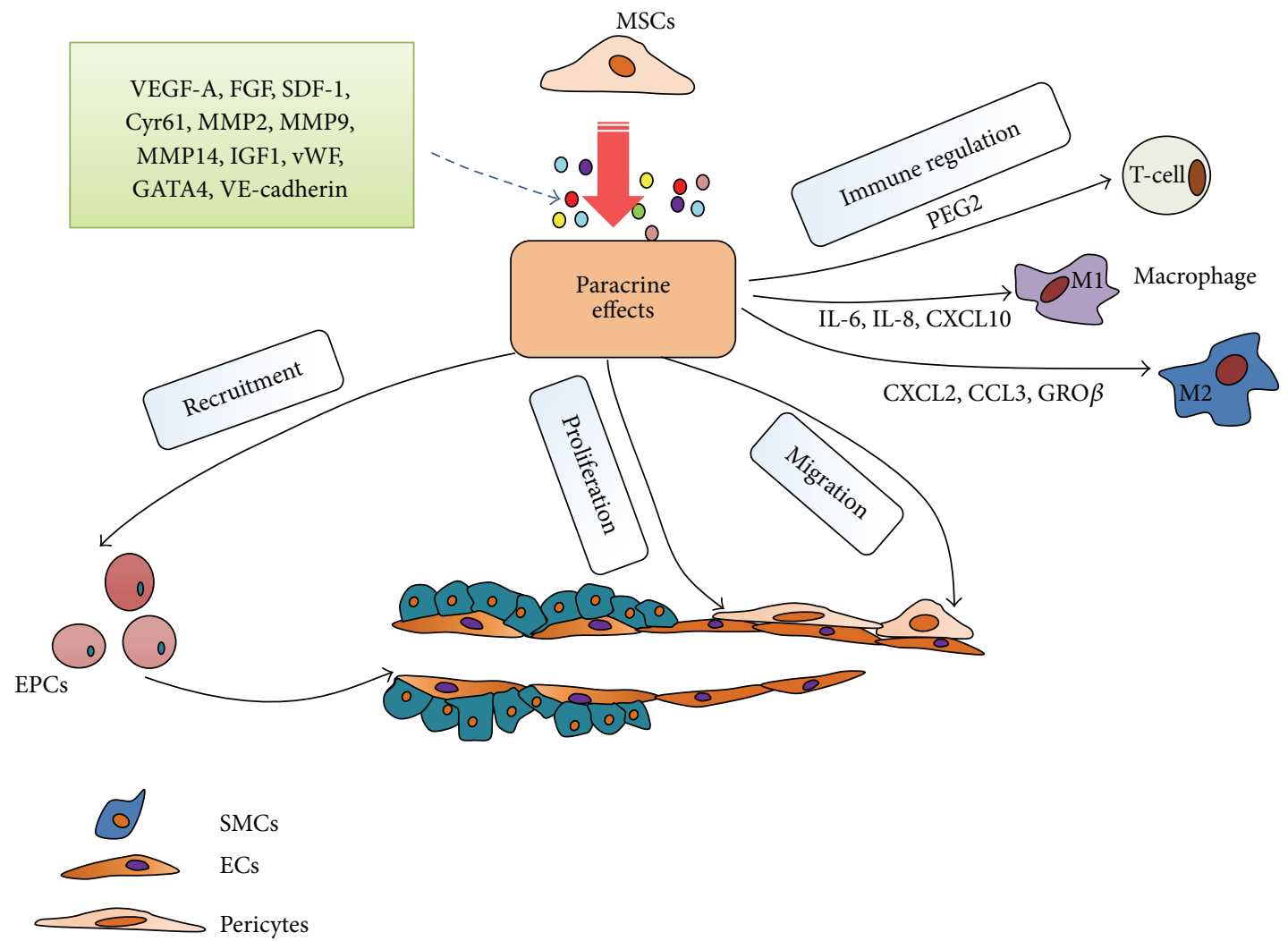

FIGURE 2: Proangiogenic roles of MSCs. MSCs promote angiogenesis by (1) secreting proangiogenic bioactive factors; (2) functioning as pericytes to support EC proliferation and maturation; (3) recruiting EPCs and other progenitor cells into neoblood vessels; (4) regulating the immune response of the microenvironment by modulating recruitment of immune cells.

renal medulla, renal pelvis, heart, lung, small intestine, and testis $[108,109]$. Our laboratory and others have shown that GHRH receptors are also expressed on MSCs [20, 110].

4.2. GHRH Analogue Exerts Similar Effect as Proangiogenesis Ability of MSCs. GHRH and its analogues promote cell proliferation in multiple target tissues by binding and activating the GHRH receptor. GHRH analogues may have improved therapeutic properties compared with the parent GHRH. GHRH analogues have been shown to augment VEGF-A secretion in the contexts of neuroendocrine tumor cells and myocardial infarction $[1,2]$. It was recently shown that treatment of MSCs from S-nitrosoglutathione reductase (GSNOR) knockout mice with a GHRH analogue JI-38 enhanced VEGF production and stimulated the angiogenic potential of JI-38-treated MSCs [20]. JI-38 appears to stimulate a paracrine circuit by binding to GHRH-R on MSCs promoting VEGF secretion and proangiogenesis.

4.3. Regulation of MSC Proliferation by GHRH Agonists. In one of its classical pathways, GHRH stimulates cell cycle entry and proliferation via activating adenylate cyclase and subsequently stimulating PKA to increase influx of $\mathrm{Ca}^{2+}$ through plasma membranes [111, 112]. GHRH stimulation also activates phospholipase C (PLC), increasing the production of inositol phosphates (IP) and diacylglycerol (DAG) and activating $\mathrm{PKC}$ in pituitary somatotrophs [113]. The same signaling pathways may cause enhanced proliferation by GHRH agonists and other factors when GHRH-Rs are activated in MSCs. Previous studies confirmed classic signal activation by cAMP and PKA in MSCs. In addition, a new factor, Epac1, was discovered as an exchange protein activated by cAMP, which leads to the activation of Ras-related protein 1 (Rap1) to further trigger the Akt phosphorylation. Activated (p)-Akt is a central regulator of insulin and IGF-1 signaling and can promote translocation of $\beta$-catenin to nucleus to augment the expression of c-myc and VEGF thereby controlling MSC proliferation [114].

As discussed earlier in this review, GHRH and its agonists promote the proliferation of pituitary cells through the activation of ERK1/2 and JAK/STAT3 signaling pathways [115]. These pathways are also required for GHRH to activate MSC proliferation. Indeed, the canonical mitogen-activated protein kinase (MAPK) signaling systems are well known to exert major control over cell metabolism, growth, differentiation, and cell death/survival pathways. Jaiswal et al. recently reported that MAPK is centrally involved in the process of proliferation and differentiation of human MSCs into osteogenic lineage [116]. GHRH agonists and analogues are likely to use to the same pathways to stimulate MSC proliferation. 


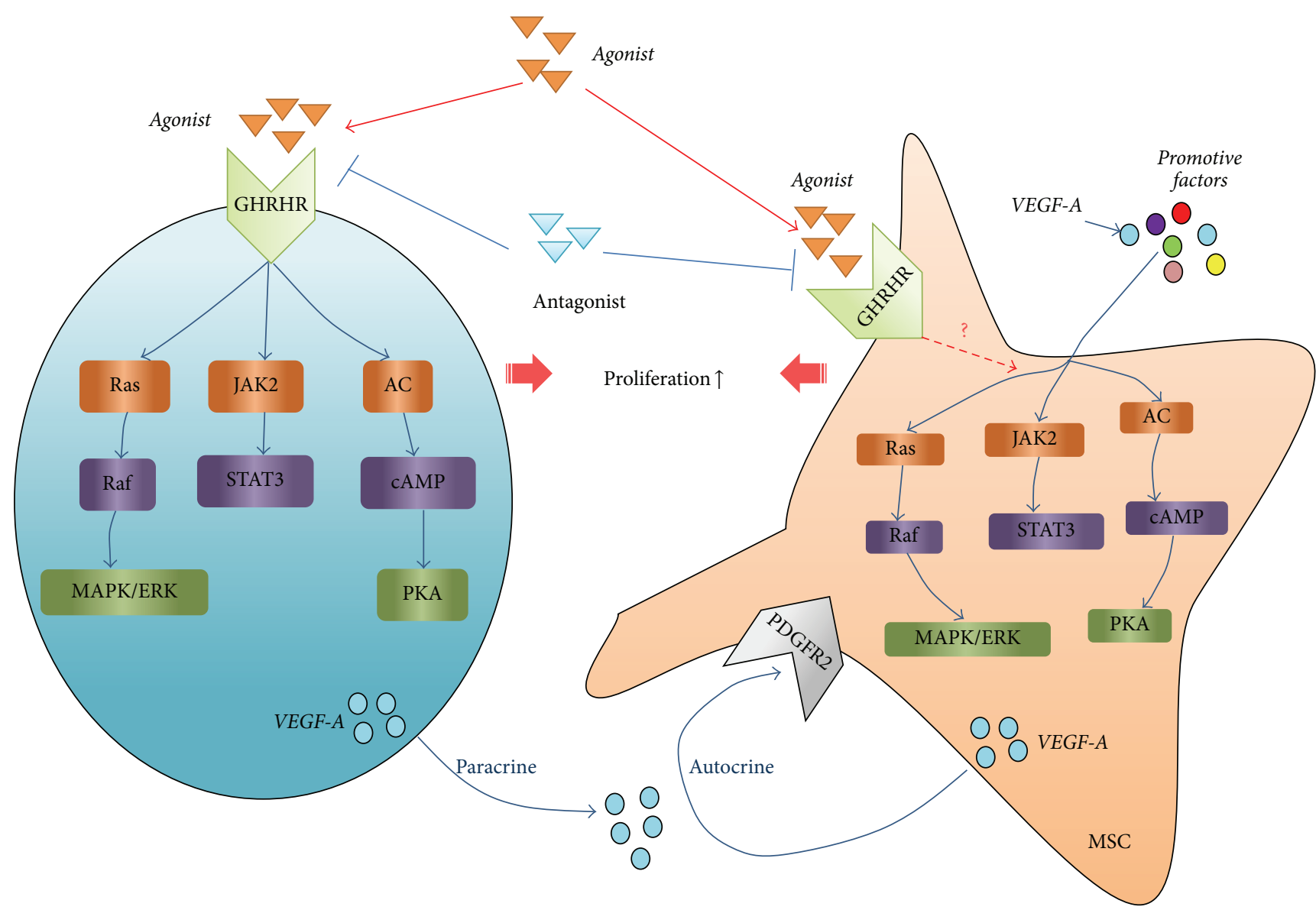

FIGURE 3: Effects of GHRH agonists on MSCs. Multiple cell types including MSCs express the GHRH receptor and can respond to GHRH agonists and antagonists. Receptor activation communicates with diverse survival pathways that transmit paracrine and autocrine signals to promote cytoprotection, antiapoptosis, and angiogenesis.

4.4. Antiproliferative Role of GHRH Antagonists on Neoplasms. GHRH and its receptor have been found in many tumor cell lines and neoplasms [111, 117-119]. GHRH can stimulate tumor growth through the GHRH/GH/IGF-1 axis and local GHRH stimulatory loops between GHRH and its receptor. By obstructing the interaction of GHRH with its receptor using an GHRH antagonist, it should be possible to prevent or reduce tumor cell hyperplasia by this pathway [1]. Molecules known to play important roles in cell proliferation including cAMP, PKC, and p21 have been shown to be the effective inhibited targets of GHRH antagonists for their antiproliferation and tumor suppressive actions [37, 120, 121]. These signaling intermediates also regulate MSCs proliferation.

4.5. Direct Effect of GHRH Agonists on MSCs. Treatment of MSCs with GHRH agonist JI-34 was shown to significantly increase VEGF expression in human MSCs [20]. Recently we reported that pretreatment of MSCs with GHRH agonist JI38 stimulated cell proliferation, ameliorated apoptosis caused by hypoxia and serum deprivation, and enhanced the proangiogenesis conferred when pretreated cells were injected into ischemic hindlimbs of mice [110]. This is the first report to implicate direct interactions between an GHRH agonist and
MSCs. In another report, pretreatment of ckit+ cardiac stem cells with JI-38 also conferred significant cytoprotection that was attributed to activation of ERK and Akt survival pathway [122]. Similar pathways may mediate the effects of JI-38 on MSCs described by our group. The avenues whereby GHRH agonists may enhance cytoprotection and angiogenesis are summarized in Figure 3.

\section{Clinical Prospects}

So far GHRH analogues have shown promise in preclinical studies. For other hypothalamic hormones, many clinical applications already exist. As early as 1971, Schally et al. isolated luteinizing hormone-releasing hormone (LH-RH) and later introduced analogues of LH-RH into clinical use as antitumor drugs [123]. These studies were extended to advanced endocrine therapy for hormone-related diseases. Schally's team also were the first to describe GHRH antagonists and their possible application for cancer treatment [124]. The recent demonstrations by our group and others, respectively, that JI-38 markedly enhanced the functional properties and potential therapy by MSCs and cardiac stem cells in different models of ischemia raise the possibility that 
GHRH agonists may be useful agents to augment clinical cell therapy. At the present time MSCs or cardiac stem cells are the leading candidates for such therapy. Because multiple approaches have been used for "precondition" it will be important to compare safety and efficacy side by side in the same study to determine the optimal conditions for clinical trials.

\section{Conclusion}

GHRH and its analogues regulate cell growth, proliferation, differentiation, and survival through complex networks of signaling pathways involving GHRH/GH/IGF-1 and/or local activation of GHRH receptors on extrapituitary systems and paracrine/autocrine loops. Agonists of GHRH can induce a prolonged stimulation of growth and proliferation via the cAMP/PKA and ERK and JAK2/STAT3 signaling pathways, while the antagonists of GHRH block these effects by competitively binding to the receptor. Regulation by GHRH analogues of the proliferation of normal tissues and neoplasms provides for promising approaches to clinical treatments directed at tissue repair and antitumor treatments.

MSCs are leading candidates for tissue repair and angiogenesis. The superiority of MSCs is attributed to their pluripotency, immune-privilege, and rich factories of secreted paracrine factors that enhance cell survival and confer cytoprotection and angiogenesis. GHRH agonists are one of several potential candidates that confer a powerful "preconditioning" effect to MSCs that enhances viability, mobility, and therapeutic potential. Through the activation of GHRH receptors on the surface of MSCs, GHRH agonists exert cytoprotection of MSCs and confer enhanced angiogenesis. The current results warrant further studies to compare different preconditioning strategies and begin the process of translating the most promising to clinical trials.

\section{Competing Interests}

The authors declare that no competing financial interests exist.

\section{Acknowledgments}

The authors thank Dr. Keith A. Webster, Dr. Xiaoping Lin, and Ms. Na Zhang for their input on this paper. This work was supported by National Natural Science Foundation of China (no. 31271585), Ministry of Science and Technology of China (2012CBA1305), and Zhejiang Provincial Natural Science Foundation (2013C24009).

\section{References}

[1] T. Stepień, M. Sacewicz, H. Ławnicka et al., "Stimulatory effect of growth hormone-releasing hormone (GHRH(1-29)NH2) on the proliferation, VEGF and chromogranin A secretion by human neuroendocrine tumor cell line NCI-H727 in vitro," Neuropeptides, vol. 43, no. 5, pp. 397-400, 2009.

[2] R. M. Kanashiro-Takeuchi, L. M. Takeuchi, F. G. Rick et al., "Activation of growth hormone releasing hormone (GHRH) receptor stimulates cardiac reverse remodeling after myocardial infarction (MI)," Proceedings of the National Academy of Sciences of the United States of America, vol. 109, no. 2, pp. 559-563, 2012.

[3] A. Plonowski, A. V. Schally, M. Letsch et al., "Inhibition of proliferation of PC-3 human prostate cancer by antagonists of growth hormone-releasing hormone: lack of correlation with the levels of serum IGF-I and expression of tumoral IGF-II and vascular endothelial growth factor," Prostate, vol. 52, no. 3, pp. 173-182, 2002.

[4] J. B. Engel, G. Keller, A. V. Schally et al., "Inhibition of growth of experimental human endometrial cancer by an antagonist of growth hormone-releasing hormone," Journal of Clinical Endocrinology and Metabolism, vol. 90, no. 6, pp. 3614-3621, 2005.

[5] C. A. Kanashiro, A. V. Schally, M. Zarandi, B. D. Hammann, and J. L. Varga, "Alterations of EGFR/HER, angiogenesis and apoptosis pathways after therapy with antagonists of growth hormone releasing hormone and bombesin in non-small cell lung cancer," International Journal of Oncology, vol. 30, no. 4, pp. 1019-1028, 2007.

[6] A. Klukovits, A. V. Schally, L. Szalontay et al., "Novel antagonists of growth hormone-releasing hormone inhibit growth and vascularization of human experimental ovarian cancers," Cancer, vol. 118, no. 3, pp. 670-680, 2012.

[7] M. Dominici, K. Le Blanc, I. Mueller et al., "Minimal criteria for defining multipotent mesenchymal stromal cells. The International Society for Cellular Therapy position statement," Cytotherapy, vol. 8, no. 4, pp. 315-317, 2006.

[8] M. Crisan, S. Yap, L. Casteilla et al., "A perivascular origin for mesenchymal stem cells in multiple human organs," Cell Stem Cell, vol. 3, no. 3, pp. 301-313, 2008.

[9] V. Karantalis and J. M. Hare, "Use of mesenchymal stem cells for therapy of cardiac disease," Circulation Research, vol. 116, no. 8, pp. 1413-1430, 2015.

[10] R. Estrada, N. Li, H. Sarojini, J. An, M.-J. Lee, and E. Wang, "Secretome from mesenchymal stem cells induces angiogenesis via Cyr61," Journal of Cellular Physiology, vol. 219, no. 3, pp. 563571, 2009.

[11] J. P. Laurila, L. Laatikainen, M. D. Castellone et al., "Human embryonic stem cell-derived mesenchymal stromal cell transplantation in a rat hind limb injury model," Cytotherapy, vol. 11, no. 6, pp. 726-737, 2009.

[12] L. Kucerova, M. Matuskova, K. Hlubinova, V. Altanerova, and C. Altaner, "Tumor cell behaviour modulation by mesenchymal stromal cells," Molecular Cancer, vol. 9, article 129, 2010.

[13] S. A. Fisher, C. Doree, A. Mathur, and E. Martin-Rendon, "Meta-analysis of cell therapy trials for patients with heart failure," Circulation Research, vol. 116, no. 8, pp. 1361-1377, 2015.

[14] H. Chen, X. Liu, W. Zhu et al., "SIRT1 ameliorates age-related senescence of mesenchymal stem cells via modulating telomere shelterin," Frontiers in Aging Neuroscience, vol. 6, article 103, 2014.

[15] X. Hu, R. Wu, Z. Jiang et al., "Leptin signaling is required for augmented therapeutic properties of mesenchymal stem cells conferred by hypoxia preconditioning," STEM CELLS, vol. 32, no. 10, pp. 2702-2713, 2014.

[16] X. Hu, R. Wu, L. A. Shehadeh et al., "Severe hypoxia exerts parallel and cell-specific regulation of gene expression and alternative splicing in human mesenchymal stem cells," $B M C$ Genomics, vol. 15, no. 1, article 303, 2014.

[17] X. Q. Hou, X. J. Wu, J. X. Ma, X. H. Lv, and X. Jin, "Erythropoietin augments the efficacy of therapeutic angiogenesis induced 
by allogenic bone marrow stromal cells in a rat model of limb ischemia," Molecular Biology Reports, vol. 37, no. 3, pp. 14671475, 2010.

[18] A. N. Smith, L. A. Muffley, A. N. Bell, S. Numhom, and A. M. Hocking, "Unsaturated fatty acids induce mesenchymal stem cells to increase secretion of angiogenic mediators," Journal of Cellular Physiology, vol. 227, no. 9, pp. 3225-3233, 2012.

[19] R. Granata, J. Isgaard, G. Alloatti, and E. Ghigo, "Cardiovascular actions of the ghrelin gene-derived peptides and growth hormone-releasing hormone," Experimental Biology and Medicine, vol. 236, no. 5, pp. 505-514, 2011.

[20] S. A. Gomes, E. B. Rangel, C. Premer et al., "S-nitrosoglutathione reductase (GSNOR) enhances vasculogenesis by mesenchymal stem cells," Proceedings of the National Academy of Sciences of the United States of America, vol. 110, no. 8, pp. 28342839, 2013.

[21] A. Siejka, N. Barabutis, and A. V. Schally, "GHRH antagonist inhibits focal adhesion kinase (FAK) and decreases expression of vascular endothelial growth factor (VEGF) in human lung cancer cells in vitro," Peptides, vol. 37, no. 1, pp. 63-68, 2012.

[22] L. Muñoz-Moreno, M. I. Arenas, A. V. Schally et al., "Inhibitory effects of antagonists of growth hormone-releasing hormone on growth and invasiveness of PC3 human prostate cancer," International Journal of Cancer, vol. 132, no. 4, pp. 755-765, 2013.

[23] E. Pozsgai, A. V. Schally, M. Zarandi, J. L. Varga, I. Vidaurre, and S. Bellyei, "The effect of GHRH antagonists on human glioblastomas and their mechanism of action," International Journal of Cancer, vol. 127, no. 10, pp. 2313-2322, 2010.

[24] F. Köster, J. B. Engel, A. V. Schally et al., “Triple-negative breast cancers express receptors for growth hormone-releasing hormone (GHRH) and respond to GHRH antagonists with growth inhibition," Breast Cancer Research and Treatment, vol. 116, no. 2, pp. 273-279, 2009.

[25] A. Giustina and J. D. Veldhuis, "Pathophysiology of the neuroregulation of growth hormone secretion in experimental animals and the human," Endocrine Reviews, vol. 19, no. 6, pp. 717-797, 1998.

[26] G. P. Ceda, R. G. Davis, R. G. Rosenfeld, and A. R. Hoffman, "The growth hormone (GH)-releasing hormone (GHRH)-GHsomatomedin axis: evidence for rapid inhibition of GHRHelicited GH release by insulin-like growth factors I and II," Endocrinology, vol. 120, no. 4, pp. 1658-1662, 1987.

[27] M. R. Ehlers, "Recombinant human GHRH(1-44) $\mathrm{NH}_{2}$ : clinical utility and therapeutic development program," Endocrine, vol. 14, no. 1, pp. 137-141, 2001.

[28] K. E. Mayo, T. Miller, V. DeAlmeida et al., "Regulation of the pituitary somatotroph cell by GHRH and its receptor," Recent Progress in Hormone Research, vol. 55, pp. 237-267, 2000.

[29] J. Izdebski, J. Pinski, J. E. Horvath, G. Halmos, K. Groot, and A. V. Schally, "Synthesis and biological evaluation of superactive agonists of growth hormone-releasing hormone," Proceedings of the National Academy of Sciences of the United States of America, vol. 92, no. 11, pp. 4872-4876, 1995.

[30] M. Korbonits and A. B. Grossman, "Growth hormone-releasing peptide and its analogues. Novel stimuli to growth hormone release," Trends in Endocrinology and Metabolism, vol. 6, no. 2, pp. 43-49, 1995.

[31] N. Dioufa, A. V. Schally, I. Chatzistamou et al., "Acceleration of wound healing by growth hormone-releasing hormone and its agonists," Proceedings of the National Academy of Sciences of the United States of America, vol. 107, no. 43, pp. 18611-18615, 2010.
[32] H. Kiaris, A. V. Schally, R. Busto, G. Halmos, S. ArtavanisTsakonas, and J. L. Varga, "Expression of a splice variant of the receptor for GHRH in $3 \mathrm{~T} 3$ fibroblasts activates cell proliferation responses to GHRH analogs," Proceedings of the National Academy of Sciences of the United States of America, vol. 99, no. 1, pp. 196-200, 2002.

[33] R. Granata, L. Trovato, M. P. Gallo et al., "Growth hormonereleasing hormone promotes survival of cardiac myocytes in vitro and protects against ischaemia-reperfusion injury in rat heart," Cardiovascular Research, vol. 83, no. 2, pp. 303-312, 2009.

[34] C. Penna, F. Settanni, F. Tullio et al., "GH-releasing hormone induces cardioprotection in isolated male rat heart via activation of RISK and SAFE pathways," Endocrinology, vol. 154, no. 4, pp. 1624-1635, 2013.

[35] L. L. Bagno, R. M. Kanashiro-Takeuchi, V. Y. Suncion et al., "Growth hormone-releasing hormone agonists reduce myocardial infarct scar in swine with subacute ischemic cardiomyopathy," Journal of the American Heart Association, vol. 4, no. 4, Article ID e001464, 2015.

[36] R. M. Kanashiro-Takeuchi, L. Szalontay, A. V. Schally et al., "New therapeutic approach to heart failure due to myocardial infarction based on targeting growth hormone-releasing hormone receptor," Oncotarget, vol. 6, no. 12, pp. 9728-9739, 2015.

[37] V. Csernus, A. V. Schally, and K. Groot, "Antagonistic analogs of growth hormone releasing hormone (GHRH) inhibit cyclic AMP production of human cancer cell lines in vitro," Peptides, vol. 20, no. 7, pp. 843-850, 1999.

[38] K. Szepeshazi, A. V. Schally, K. Groot et al., "Antagonists of growth hormone-releasing hormone (GH-RH) inhibit IGF-II production and growth of HT-29 human colon cancers," British Journal of Cancer, vol. 82, no. 10, pp. 1724-1731, 2000.

[39] P. Zeitler and G. Siriwardana, "Antagonism of endogenous growth hormone-releasing hormone (GHRH) leads to reduced proliferation and apoptosis in MDA231 breast cancer cells," Endocrine, vol. 18, no. 1, pp. 85-90, 2002.

[40] F. Hohla, A. V. Schally, K. Szepeshazi et al., "Synergistic inhibition of growth of lung carcinomas by antagonists of growth hormone-releasing hormone in combination with docetaxel," Proceedings of the National Academy of Sciences of the United States of America, vol. 103, no. 39, pp. 14513-14518, 2006.

[41] J. Guo, A. V. Schally, M. Zarandi, J. Varga, and P. C. K. Leung, "Antiproliferative effect of growth hormone-releasing hormone (GHRH) antagonist on ovarian cancer cells through the EGFRAkt pathway," Reproductive Biology and Endocrinology, vol. 8, article 54, 2010.

[42] L. Szalontay, R. J. Benveniste, A. V. Schally et al., "Inhibitory effects of GHRH antagonists on human GH-secreting adenoma tissue," Neuroendocrinology, vol. 96, no. 1, pp. 81-88, 2012.

[43] N. Barabutis and A. V. Schally, "Growth hormone-releasing hormone: extrapituitary effects in physiology and pathology," Cell Cycle, vol. 9, no. 20, pp. 4110-4116, 2010.

[44] U. Schubert, J. Schmid, S. Lehmann et al., "Transplantation of pancreatic islets to adrenal gland is promoted by agonists of growth-hormone-releasing hormone," Proceedings of the National Academy of Sciences of the United States of America, vol. 110, no. 6, pp. 2288-2293, 2013.

[45] R. Z. Cai, A. V. Schally, T. J. Cui et al., "Synthesis of new potent agonistic analogs of growth hormone-releasing hormone (GHRH) and evaluation of their endocrine and cardiac activities," Peptides, vol. 52, pp. 104-112, 2014.

[46] Z. Kahán, J. M. Arencibia, V. J. Csernus et al., "Expression of growth hormone-releasing hormone (GHRH) messenger 
ribonucleic acid and the presence of biologically active GHRH in human breast, endometrial, and ovarian cancers," Journal of Clinical Endocrinology and Metabolism, vol. 84, no. 2, pp. 582589, 1999.

[47] A. Siejka, H. Lawnicka, G. Melen-Mucha, E. Motylewska, J. Komorowski, and H. Stepien, "Antineoplastic action of growth hormone-releasing hormone (GHRH) antagonists," Recent Patents on Anti-Cancer Drug Discovery, vol. 7, no. 1, pp. 56-63, 2012.

[48] G. Siriwardana, A. Bradford, D. Coy, and P. Zeitler, "Autocrine/ paracrine regulation of breast cancer cell proliferation by growth hormone releasing hormone via Ras, Raf, and mitogenactivated protein kinase," Molecular Endocrinology, vol. 20, no. 9, pp. 2010-2019, 2006.

[49] F. G. Rick, A. V. Schally, L. Szalontay et al., "Antagonists of growth hormone-releasing hormone inhibit growth of androgen-independent prostate cancer through inactivation of ERK and Akt kinases," Proceedings of the National Academy of Sciences of the United States of America, vol. 109, no. 5, pp. 1655-1660, 2012.

[50] J. Folkman, "Role of angiogenesis in tumor growth and metastasis," Seminars in Oncology, vol. 29, no. 6, pp. 15-18, 2002.

[51] M. Kojima, H. Hosoda, Y. Date, M. Nakazato, H. Matsuo, and K. Kangawa, "Ghrelin is a growth-hormone-releasing acylated peptide from stomach," Nature, vol. 402, no. 6762, pp. 656-660, 1999.

[52] R. D. Kineman and R. M. Luque, "Evidence that ghrelin is as potent as Growth Hormone (GH)-Releasing Hormone $(\mathrm{GHRH})$ in releasing $\mathrm{GH}$ from primary pituitary cell cultures of a nonhuman primate (Papio anubis), acting through intracellular signaling pathways distinct from GHRH," Endocrinology, vol. 148, no. 9, pp. 4440-4449, 2007.

[53] M. Kluge, P. Schüssler, P. Bleninger et al., "Ghrelin alone or coadministered with GHRH or CRH increases non-REM sleep and decreases REM sleep in young males," Psychoneuroendocrinology, vol. 33, no. 4, pp. 497-506, 2008.

[54] C. Norman, N. Rollene, S. M. Weist et al., "Short-term estradiol supplementation potentiates low-dose Ghrelin action in the presence of GHRH or somatostatin in older women," Journal of Clinical Endocrinology and Metabolism, vol. 99, no. 1, pp. E73E80, 2014.

[55] D. van Poll, B. Parekkadan, I. H. Borel Rinkes, A. W. Tilles, and M. L. Yarmush, "Mesenchymal stem cell therapy for protection and repair of injured vital organs," Cellular and Molecular Bioengineering, vol. 1, no. 1, pp. 42-50, 2008.

[56] M.-J. Tsai, S.-K. Tsai, B.-R. Hu et al., "Recovery of neurological function of ischemic stroke by application of conditioned medium of bone marrow mesenchymal stem cells derived from normal and cerebral ischemia rats," Journal of Biomedical Science, vol. 21, no. 1, article 5, 2014.

[57] B. Huang, J. Qian, J. Ma et al., "Myocardial transfection of hypoxia-inducible factor- $1 \alpha$ and co-transplantation of mesenchymal stem cells enhance cardiac repair in rats with experimental myocardial infarction," Stem Cell Research and Therapy, vol. 5, no. 1, article 22, 2014.

[58] D. J. Borg, M. Weigelt, C. Wilhelm et al., "Mesenchymal stromal cells improve transplanted islet survival and islet function in a syngeneic mouse model," Diabetologia, vol. 57, no. 3, pp. 522531, 2014.

[59] Z. H. Li, W. Liao, Q. Zhao et al., "Angiogenesis and bone regeneration by allogeneic mesenchymal stem cell intravenous transplantation in rabbit model of avascular necrotic femoral head," Journal of Surgical Research, vol. 183, no. 1, pp. 193-203, 2013.

[60] K. C. Wollert, G. P. Meyer, J. Lotz et al., "Intracoronary autologous bone-marrow cell transfer after myocardial infarction: the BOOST randomised controlled clinical trial," The Lancet, vol. 364, no. 9429, pp. 141-148, 2004.

[61] V. Schächinger, T. Tonn, S. Dimmeler, and A. M. Zeiher, "Bonemarrow-derived progenitor cell therapy in need of proof of concept: design of the REPAIR-AMI trial," Nature Clinical Practice Cardiovascular Medicine, vol. 3, supplement 1, pp. S23S28, 2006.

[62] M. Gyöngyösi, I. Lang, M. Dettke et al., "Combined delivery approach of bone marrow mononuclear stem cells early and late after myocardial infarction: the MYSTAR prospective, randomized study," Nature Clinical Practice Cardiovascular Medicine, vol. 6, no. 1, pp. 70-81, 2009.

[63] S. H. Ranganath, O. Levy, M. S. Inamdar, and J. M. Karp, "Harnessing the mesenchymal stem cell secretome for the treatment of cardiovascular disease," Cell Stem Cell, vol. 10, no. 3, pp. 244-258, 2012.

[64] S. M. Watt, F. Gullo, M. Van Der Garde et al., "The angiogenic properties of mesenchymal stem/stromal cells and their therapeutic potential," British Medical Bulletin, vol. 108, no. 1, pp. 25-53, 2013.

[65] A. I. Caplan and J. E. Dennis, "Mesenchymal stem cells as trophic mediators," Journal of Cellular Biochemistry, vol. 98, no. 5, pp. 1076-1084, 2006.

[66] C. M. Ghajar, S. Kachgal, E. Kniazeva et al., "Mesenchymal cells stimulate capillary morphogenesis via distinct proteolytic mechanisms," Experimental Cell Research, vol. 316, no. 5, pp. 813-825, 2010.

[67] U. Tigges, M. Komatsu, and W. B. Stallcup, "Adventitial pericyte progenitor/mesenchymal stem cells participate in the restenotic response to arterial injury," Journal of Vascular Research, vol. 50, no. 2, pp. 134-144, 2013.

[68] C. Premer, A. Blum, M. A. Bellio et al., "Allogeneic mesenchymal stem cells restore endothelial function in heart failure by stimulating endothelial progenitor cells," EBioMedicine, vol. 2, no. 5, pp. 467-475, 2015.

[69] K. Le Blanc and D. Mougiakakos, "Multipotent mesenchymal stromal cells and the innate immune system," Nature Reviews Immunology, vol. 12, no. 5, pp. 383-396, 2012.

[70] N. Heldring, I. Mäger, M. J. A. Wood, K. Le Blanc, and S. E. L. Andaloussi, "Therapeutic potential of multipotent mesenchymal stromal cells and their extracellular vesicles," Human Gene Therapy, vol. 26, no. 8, pp. 506-517, 2015.

[71] M. S. Khubutiya, A. V. Vagabov, A. A. Temnov, and A. N. Sklifas, "Paracrine mechanisms of proliferative, anti-apoptotic and anti-inflammatory effects of mesenchymal stromal cells in models ofacute organ injury," Cytotherapy, vol. 16, no. 5, pp. 579-585, 2014.

[72] T. Iwase, N. Nagaya, T. Fujii et al., "Comparison of angiogenic potency between mesenchymal stem cells and mononuclear cells in a rat model of hindlimb ischemia," Cardiovascular Research, vol. 66, no. 3, pp. 543-551, 2005.

[73] H. Li, S. Zuo, Z. He et al., "Paracrine factors released by GATA4 overexpressed mesenchymal stem cells increase angiogenesis and cell survival," American Journal of Physiology-Heart and Circulatory Physiology, vol. 299, no. 6, pp. H1772-H1781, 2010. 
[74] S. Pati, A. Y. Khakoo, J. Zhao et al., "Human mesenchymal stem cells inhibit vascular permeability by modulating vascular endothelial cadherin/ $\beta$-catenin signaling," Stem Cells and Development, vol. 20, no. 1, pp. 89-101, 2011.

[75] L. D. S. Meirelles, P. C. Chagastelles, and N. B. Nardi, "Mesenchymal stem cells reside in virtually all post-natal organs and tissues," Journal of Cell Science, vol. 119, no. 11, pp. 2204-2213, 2006.

[76] I. R. Murray, C. C. West, W. R. Hardy et al., "Natural history of mesenchymal stem cells, from vessel walls to culture vessels," Cellular and Molecular Life Sciences, vol. 71, no. 8, pp. 1353-1374, 2014.

[77] A. Caplan, "Why are MSCs therapeutic? New data: new insight," The Journal of Pathology, vol. 217, no. 2, pp. 318-224, 2009.

[78] D. Bexell, S. Gunnarsson, A. Tormin et al., "Bone marrow multipotent mesenchymal stroma cells act as pericyte-like migratory vehicles in experimental gliomas," Molecular Therapy, vol. 17, no. 1, pp. 183-190, 2009.

[79] W.-M. Yue, W. Liu, Y.-W. Bi et al., "Mesenchymal stem cells differentiate into an endothelial phenotype, reduce neointimal formation, and enhance endothelial function in a rat vein grafting model," Stem Cells and Development, vol. 17, no. 4, pp. 785-793, 2008.

[80] N. M. S. Van Den Akker, F. F. Kolk, F. Jeukens et al., "Vascular potency of sus scrofa bone marrow-derived mesenchymal stem cells: a progenitor source of medial but not endothelial cells," Tissue Engineering Part A, vol. 18, no. 7-8, pp. 828-839, 2012.

[81] C.-H. Wang, T.-M. Wang, T.-H. Young, Y.-K. Lai, and M.-L. Yen, "The critical role of ECM proteins within the human MSC niche in endothelial differentiation," Biomaterials, vol. 34, no. 17, pp. 4223-4234, 2013.

[82] N. Wang, R. Zhang, S.-J. Wang et al., "Vascular endothelial growth factor stimulates endothelial differentiation from mesenchymal stem cells via Rho/myocardin-related transcription factor-a signaling pathway," International Journal of Biochemistry and Cell Biology, vol. 45, no. 7, pp. 1447-1456, 2013.

[83] X. F. Zhang, Y. Y. Nan, H. Wang et al., "Model microgravity enhances endothelium differentiation of mesenchymal stem cells," Naturwissenschaften, vol. 100, no. 2, pp. 125-133, 2013.

[84] L. Coultas, K. Chawengsaksophak, and J. Rossant, "Endothelial cells and VEGF in vascular development," Nature, vol. 438, no. 7070, pp. 937-945, 2005.

[85] J. Hur, C.-H. Yoon, H.-S. Kim et al., "Characterization of two types of endothelial progenitor cells and their different contributions to neovasculogenesis," Arteriosclerosis, Thrombosis, and Vascular Biology, vol. 24, no. 2, pp. 288-293, 2004.

[86] R. E. Geuze, F. Wegman, F. C. Öner, W. J. A. Dhert, and J. Alblas, "Influence of endothelial progenitor cells and platelet gel on tissue-engineered bone ectopically in goats," Tissue Engineering Part A, vol. 15, no. 11, pp. 3669-3677, 2009.

[87] A. Aguirre, J. A. Planell, and E. Engel, "Dynamics of bone marrow-derived endothelial progenitor cell/mesenchymal stem cell interaction in co-culture and its implications in angiogenesis," Biochemical and Biophysical Research Communications, vol. 400, no. 2, pp. 284-291, 2010.

[88] C. Seebach, D. Henrich, K. Wilhelm, J. H. Barker, and I. Marzi, "Endothelial progenitor cells improve directly and indirectly early vascularization of mesenchymal stem cell-driven bone regeneration in a critical bone defect in rats," Cell Transplantation, vol. 21, no. 8, pp. 1667-1677, 2012.

[89] A. Burlacu, G. Grigorescu, A.-M. Rosca, M. B. Preda, and M. Simionescu, "Factors secreted by mesenchymal stem cells and endothelial progenitor cells have complementary effects on angiogenesis in vitro," Stem Cells and Development, vol. 22, no. 4, pp. 643-653, 2013.

[90] S. Rafii, S. Meeus, S. Dias et al., "Contribution of marrowderived progenitors to vascular and cardiac regeneration," Seminars in Cell and Developmental Biology, vol. 13, no. 1, pp. 61-67, 2002.

[91] B. G. Cuiffo and A. E. Karnoub, "Mesenchymal stem cells in tumor development: emerging roles and concepts," Cell Adhesion and Migration, vol. 6, no. 3, pp. 220-230, 2012.

[92] F. Liotta, R. Angeli, L. Cosmi et al., "Toll-like receptors 3 and 4 are expressed by human bone marrow-derived mesenchymal stem cells and can inhibit their T-cell modulatory activity by impairing notch signaling," STEM CELLS, vol. 26, no. 1, pp. 279289, 2008.

[93] L. Chen, E. E. Tredget, P. Y. G. Wu, and Y. Wu, "Paracrine factors of mesenchymal stem cells recruit macrophages and endothelial lineage cells and enhance wound healing," PLoS ONE, vol. 3, no. 4, Article ID e1886, 2008.

[94] R. Hass and A. Otte, "Mesenchymal stem cells as all-round supporters in a normal and neoplastic microenvironment," Cell Communication and Signaling, vol. 10, article 26, 2012.

[95] J.-A. Wang, T.-L. Chen, J. Jiang et al., "Hypoxic preconditioning attenuates hypoxia/reoxygenation-induced apoptosis in mesenchymal stem cells," Acta Pharmacologica Sinica, vol. 29, no. 1, pp. 74-82, 2008.

[96] J. G. Rasmussen, O. Frøbert, L. Pilgaard et al., "Prolonged hypoxic culture and trypsinization increase the pro-angiogenic potential of human adipose tissue-derived stem cells," Cytotherapy, vol. 13, no. 3, pp. 318-328, 2011.

[97] H. Kawasaki, J. Guan, and K. Tamama, "Hydrogen gas treatment prolongs replicative lifespan of bone marrow multipotential stromal cells in vitro while preserving differentiation and paracrine potentials," Biochemical and Biophysical Research Communications, vol. 397, no. 3, pp. 608-613, 2010.

[98] J. Zhang, G.-H. Chen, Y.-W. Wang et al., "Hydrogen peroxide preconditioning enhances the therapeutic efficacy of Wharton's jelly mesenchymal stem cells after myocardial infarction," Chinese Medical Journal, vol. 125, no. 19, pp. 3472-3478, 2012.

[99] J. L. Herrmann, Y. Wang, A. M. Abarbanell, B. R. Weil, J. Tan, and D. R. Meldrum, "Preconditioning mesenchymal stem cells with transforming growth factor-alpha improves mesenchymal stem cell-mediated cardioprotection," Shock, vol. 33, no. 1, pp. 24-30, 2010.

[100] K. Tamama, V. H. Fan, L. G. Griffith, H. C. Blair, and A. Wells, "Epidermal growth factor as a candidate for ex vivo expansion of bone marrow-derived mesenchymal stem cells," Stem Cells, vol. 24, no. 3, pp. 686-695, 2006.

[101] D. J. Rickard, F.-L. Wang, A.-M. Rodriguez-Rojas et al., "Intermittent treatment with parathyroid hormone (PTH) as well as a non-peptide small molecule agonist of the PTH1 receptor inhibits adipocyte differentiation in human bone marrow stromal cells," Bone, vol. 39, no. 6, pp. 1361-1372, 2006.

[102] M. R. Afzal, H. K. Haider, N. M. Idris, S. Jiang, R. P. H. Ahmed, and M. Ashraf, "Preconditioning promotes survival and angiomyogenic potential of mesenchymal stem cells in the infarcted heart via NF- $\kappa \mathrm{B}$ signaling," Antioxidants and Redox Signaling, vol. 12, no. 6, pp. 693-702, 2010.

[103] X. Cui, H. Wang, H. Guo et al., "Transplantation of mesenchymal stem cells preconditioned with diazoxide, a mitochondrial ATP-sensitive potassium channel opener, promotes repair of 
myocardial infarction in rats," Tohoku Journal of Experimental Medicine, vol. 220, no. 2, pp. 139-147, 2010.

[104] J. Cho, P. Zhai, Y. Maejima, and J. Sadoshima, "Myocardial injection with GSK-3 $\beta$-overexpressing bone marrow-derived mesenchymal stem cells attenuates cardiac dysfunction after myocardial infarction," Circulation Research, vol. 108, no. 4, pp. 478-489, 2011.

[105] L. Fan, C. Lin, S. Zhuo et al., "Transplantation with survivinengineered mesenchymal stem cells results in better prognosis in a rat model of myocardial infarction," European Journal of Heart Failure, vol. 11, no. 11, pp. 1023-1030, 2009.

[106] Q. P. Pham, F. K. Kasper, L. S. Baggett, R. M. Raphael, J. A. Jansen, and A. G. Mikos, "The influence of an in vitro generated bone-like extracellular matrix on osteoblastic gene expression of marrow stromal cells," Biomaterials, vol. 29, no. 18, pp. 27292739, 2008.

[107] C. Gao, E. J. Harvey, M. Chua et al., "MSC-seeded dense collagen scaffolds with a bolus dose of vegf promote healing of large bone defects," European Cells and Materials, vol. 26, pp. 195-207, 2013.

[108] S. Matsubara, M. Sato, M. Mizobuchi, M. Niimi, and J. Takahara, "Differential gene expression of growth hormone (GH)releasing hormone $(\mathrm{GRH})$ and $\mathrm{GRH}$ receptor in various rat tissues," Endocrinology, vol. 136, no. 9, pp. 4147-4150, 1995.

[109] C. Christodoulou, A. V. Schally, I. Chatzistamou et al., "Expression of growth hormone-releasing hormone (GHRH) and splice variant of GHRH receptors in normal mouse tissues," Regulatory Peptides, vol. 136, no. 1-3, pp. 105-108, 2006.

[110] Q. Ma, X. Xia, Q. Tao et al., "Profound actions of an agonist of growth hormone-releasing hormone on angiogenic therapy by mesenchymal stem cells," Arteriosclerosis, Thrombosis, and Vascular Biology, vol. 36, no. 4, pp. 663-672, 2016.

[111] M. O. Garcia-Fernandez, A. V. Schally, J. L. Varga, K. Groot, and R. Busto, "The expression of growth hormone-releasing hormone (GHRH) and its receptor splice variants in human breast cancer lines; the evaluation of signaling mechanisms in the stimulation of cell proliferation," Breast Cancer Research and Treatment, vol. 77, no. 1, pp. 15-26, 2003.

[112] E. E. Müller, V. Locatelli, and D. Cocchi, "Neuroendocrine control of growth hormone secretion," Physiological Reviews, vol. 79, no. 2, pp. 511-607, 1999.

[113] R. Xu, S.-G. Roh, K. Loneragan, M. Pullar, and C. Chen, "Human GHRH reduces voltage-gated $\mathrm{K}^{+}$currents via a noncAMP-dependent but PKC-mediated pathway in human GH adenoma cells," The Journal of Physiology, vol. 520, part 3, pp. 697-707, 1999.

[114] M. W. Jang, S. P. Yun, J. H. Park, J. M. Ryu, J. H. Lee, and H. J. Han, "Cooperation of Epac1/Rap1/Akt and PKA in prostaglandin $\mathrm{E}_{2}$-induced proliferation of human umbilical cord blood derived mesenchymal stem cells: involvement of cMyc and VEGF expression," Journal of Cellular Physiology, vol. 227, no. 12, pp. 3756-3767, 2012.

[115] A. Siejka, A. V. Schally, N. L. Block, and N. Barabutis, "Antagonists of growth hormone-releasing hormone inhibit the proliferation of human benign prostatic hyperplasia cells," Prostate, vol. 70, no. 10, pp. 1087-1093, 2010.

[116] R. K. Jaiswal, N. Jaiswal, S. P. Bruder, G. Mbalaviele, D. R. Marshak, and M. F. Pittenger, "Adult human mesenchymal stem cell differentiation to the osteogenic or adipogenic lineage is regulated by mitogen-activated protein kinase," The Journal of Biological Chemistry, vol. 275, no. 13, pp. 9645-9652, 2000.
[117] V. Csernus, A. V. Schally, and K. Groot, "Effect of GHRH and peptides from the vasoactive intestinal peptide family on cAMP production of human cancer cell lines in vitro," Journal of Endocrinology, vol. 163, no. 2, pp. 269-280, 1999.

[118] H. Kiaris, A. V. Schally, J. L. Varga, K. Groot, and P. Armatis, "Growth hormone-releasing hormone: an autocrine growth factor for small cell lung carcinoma," Proceedings of the National Academy of Sciences of the United States of America, vol. 96, no. 26, pp. 14894-14898, 1999.

[119] L. K. Chopin and A. C. Herington, "A potential autocrine pathway for growth hormone releasing hormone (GHRH) and its receptor in human prostate cancer cell lines," The Prostate, vol. 49, no. 2, pp. 116-121, 2001.

[120] C. A. Kanashiro, A. V. Schally, M. Zarandi, B. D. Hammann, and J. L. Varga, "Suppression of growth of H-69 small cell lung carcinoma by antagonists of growth hormone releasing hormone and bombesin is associated with an inhibition of protein kinase C signaling," International Journal of Cancer, vol. 112, no. 4, pp. 570-576, 2004.

[121] C. A. Kanashiro, A. V. Schally, K. Groot, P. Armatis, A. L. F. Bernardino, and J. L. Varga, "Inhibition of mutant p53 expression and growth of DMS-153 small cell lung carcinoma by antagonists of growth hormone-releasing hormone and bombesin," Proceedings of the National Academy of Sciences of the United States of America, vol. 100, no. 26, pp. 15836-15841, 2003.

[122] V. Florea, S. S. Majid, R. M. Kanashiro-Takeuchi et al., "Agonists of growth hormone-releasing hormone stimulate self-renewal of cardiac stem cells and promote their survival," Proceedings of the National Academy of Sciences of the United States of America, vol. 111, no. 48, pp. 17260-17265, 2014.

[123] G. Tolis, D. Ackman, A. Stellos et al., “Tumor growth inhibition in patients with prostatic carcinoma treated with luteinizing hormone-releasing hormone agonists," Proceedings of the National Academy of Sciences of the United States of America, vol. 79, no. 5, pp. 1658-1662, 1982.

[124] A. V. Schally, "New approaches to the therapy of various tumors based on peptide analogues," Hormone and Metabolic Research, vol. 40, no. 5, pp. 315-322, 2008. 

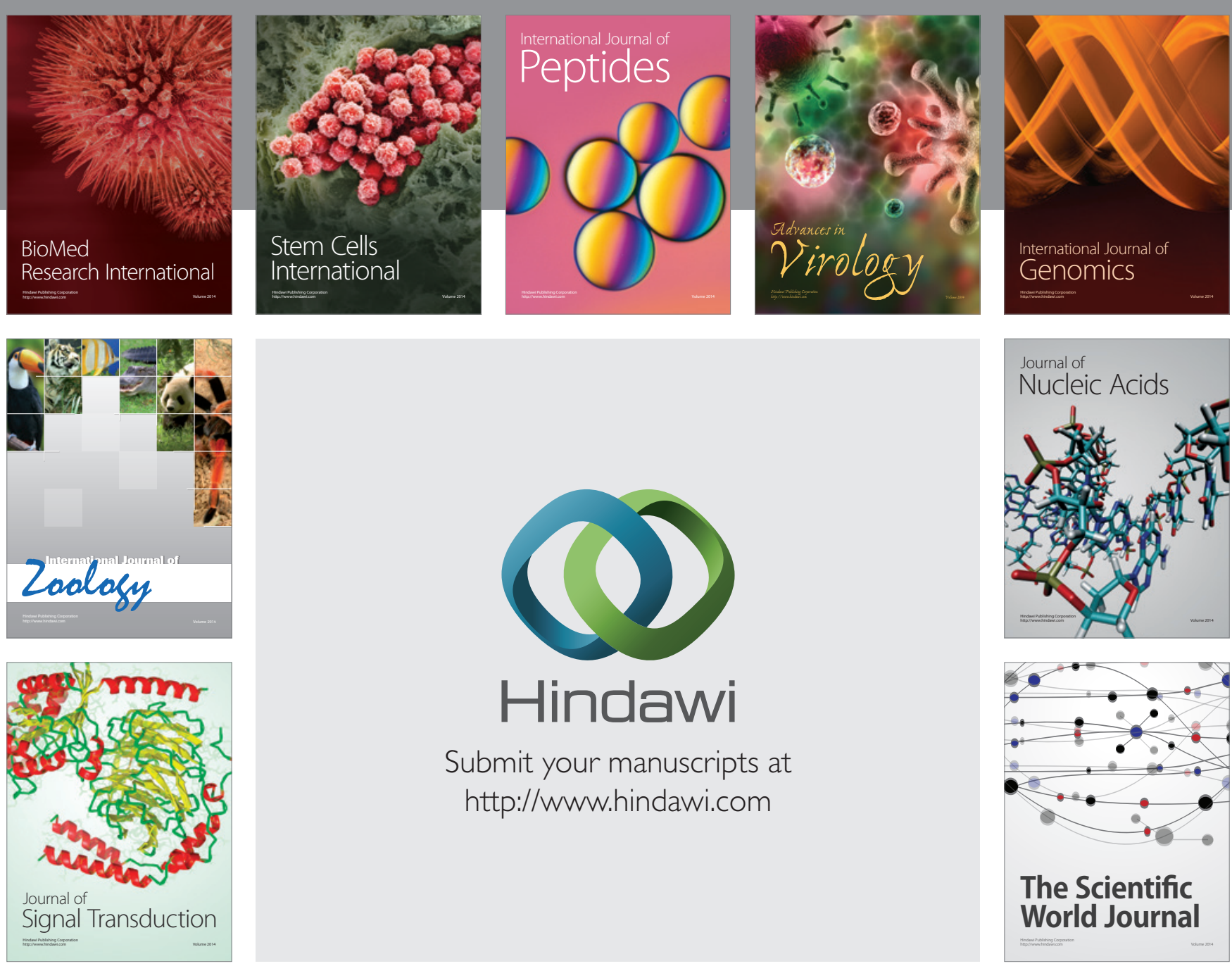

Submit your manuscripts at

http://www.hindawi.com
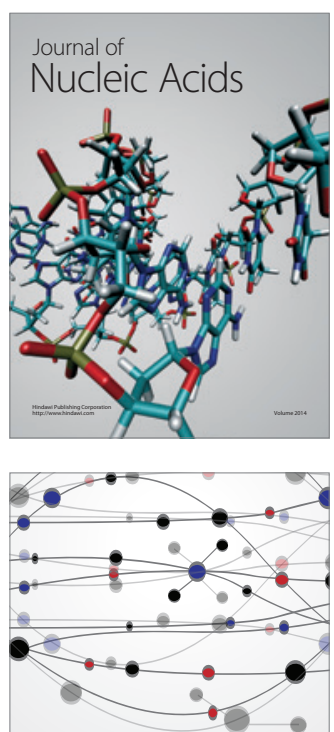

The Scientific World Journal
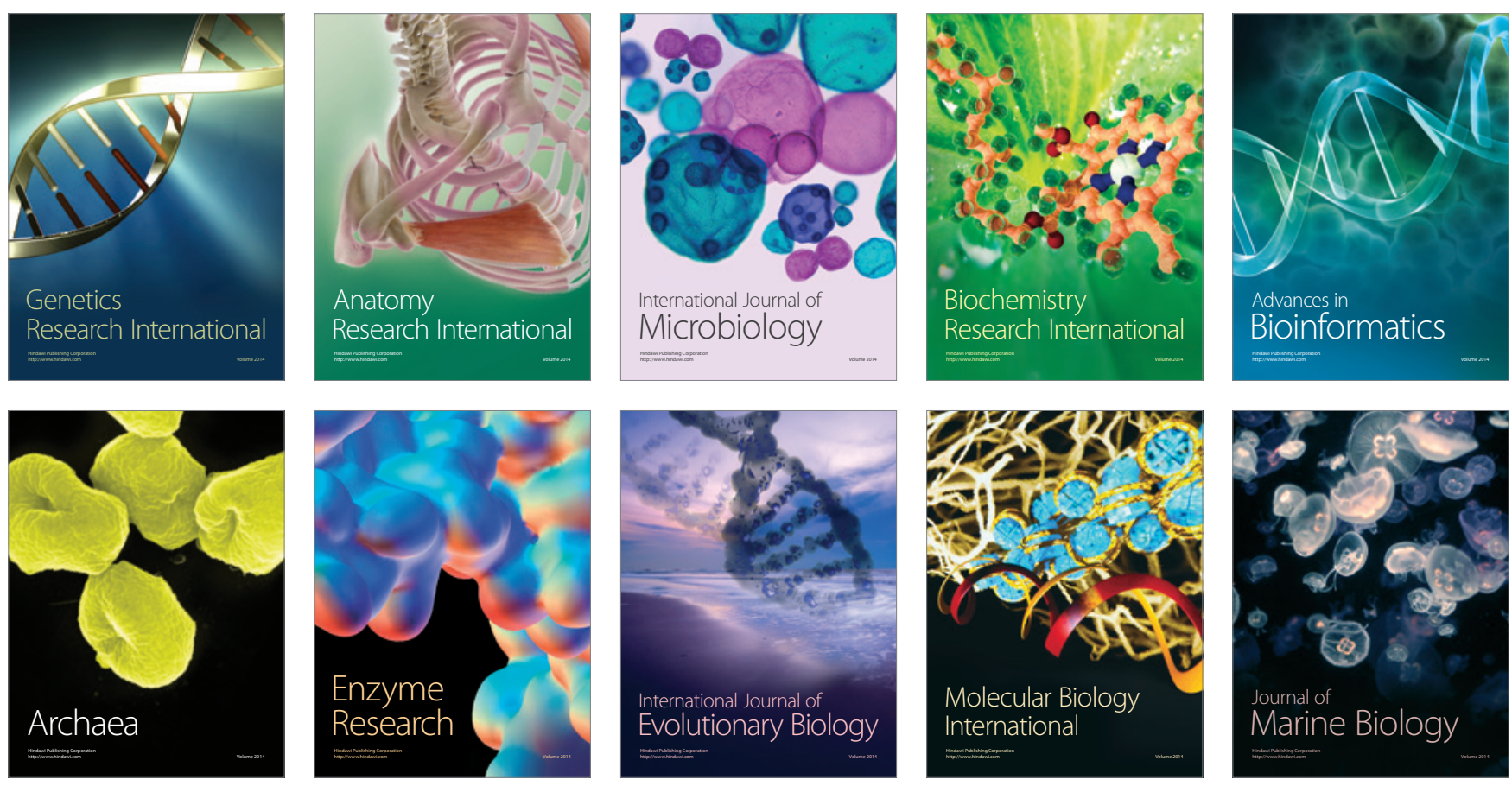